Opinion Article

\title{
HEMOSTATIC ABNORMALITIES IN COVID-19: UNDERLYING MECHANISMS AND CLUES TO TREATMENT Do we Really See a "Storm" Never Seen Before?
}

\author{
Jovan P Antovic ${ }^{1,2}$ \\ ${ }^{1}$ Coagulation, Karolinska Institutet, Department of Molecular Medicine and Surgery, Stockholm, Sweden \\ ${ }^{2}$ Karolinska University Hospital, Clinical Chemistry, Stockholm, Sweden
}

\begin{abstract}
Despite relatively short time since Covid-19 infection has appeared in the world, enormous amount of literature data (more than 20000 articles currently (mid-June)) is available on PubMed. Those data, together with our own experience at Karolinska University Hospital point towards hemostatic abnormalities in significant number of severe patients. Majority of those patients experience persistent hypercoagulation with massively increased Ddimer and fibrinogen. As a consequence, clinical thrombotic events, including venous thromboembolism (VTE) are common in Covid-19 patients and it seems that increased anticoagulant prophylaxis may be beneficial for severe (ICU/mechanical ventilation) patients. The lungs are most severely injured by the virus and that the potential underlying mechanism is a crosstalk between inflammation/complement and hemostasis. It is important to emphasize that the importance of hemostatic abnormalities in Covid-19 patients should not be overestimated since thromboembolic phenomena are, to a similar extent, present in other influenza and severely ill patients.
\end{abstract}

Key words: Covid-19, thrombosis, anticoagulant treatment, D-dimer.

\section{Introduction}

Since December 2019, severe acute respiratory syndrome coronavirus 2 (SARS-CoV-2) has spread from Wuhan in China around the world [1]. In February 2020, the WHO named the disease Covid-19. An infection with increasing mortality rates and burden on the health care system and particularly intensive care units (ICU) has been experienced around the world. Infected patients present with influenza symptoms of different severity and some suffer from severe respiratory problems [2-3].

\section{Cytokines Disturbances in Covid-19}

In severe cases, cytokine disturbances (e.g. increased interleukin (IL-1B), interferon (IFN- $\gamma$ ), and monocyte chemoattractant protein 1 (MCP-1)) have been detected in patients with Covid-19. The authors of that initial article [4] have used the term "cytokine storm" which is considered an excessive immune response to external stimuli. Readers have to be aware that the pathogenesis of the cytokine storm is complex, it progresses rapidly and is associated with high mortality. It has also been shown that the levels of IL-2R and IL-6 in patients with Covid-19 are positively correlated with the severity of the disease [5]. Due to such changes described in China

Correspondence to: Jovan P Antovic M.D., Ph.D.

L704, Karolinska University Hospital, SE- 17176 Stockholm, Sweden Phone: +468517 75637

E-mail: Jovan.Antovic@sll.se

Received June $20^{\text {th }}, 2020$ among the first patients, in one of the very first articles it has been stated that "certain evidence shows that, during the coronavirus disease 2019 (COVID-19) epidemic, the severe deterioration of some patients has been closely related to the cytokine storm in their bodies" [6]. Although this may be potentially true, we advise that this term be carefully used for patients with Covid-19 without additional evidence.

\section{Disseminated Intravascular Coagulation (DIC) in Covid-19: True or False?}

Already in February 2020, first reports about coagulation abnormalities were available on the PubMed. In one of those studies it was reported (probably not completely correctly since it is not completely clear that ISTH DIC was fully properly calculated) that $71.4 \%$ of non-survivors with Covid-19 infection meet the criteria for disseminated intravascular coagulation (DIC) [7]. Based on the first papers, in one meta-analysis the conclusion that almost 3/4 of Covid-19 patients fulfilled laboratory criteria for disseminated intravascular coagulation (DIC) was drawn [8]. The first pivotal retrospective study has demonstrated that increased levels of IL-6 were found in non-survivors in comparison to survivors but $\mathrm{D}$-dimer was considered to be an even better prognostic factor [9]. Substantially increased D-dimer and its importance for disease prognosis have been observed in other studies [10-12]. Our experience at Karolinska University Hospital is the same: massive increase of D-dimer (even values $>35 \mathrm{mg} / \mathrm{L}$ in some patients, compared to normal values of $<0,5 \mathrm{mg} / \mathrm{L}$ ). D- 
Table 1 ISTH DIC score [16]

\begin{tabular}{lccc}
\hline & 0 & 1 & 2 \\
\hline Platelet count & $>100 \times 10^{9} / \mathrm{ml}$ & $50-100 \times 10^{9} / \mathrm{ml}$ & $<50 \times 10^{9} / \mathrm{ml}$ \\
D-dimer* & No increase & Moderate increase (2) & Strong increase (3) \\
Prolonged PT & $<3 \mathrm{~s}$ & $3-6 \mathrm{~s}$ & $>6 \mathrm{~s}$ \\
Fibrinogen & $>1 \mathrm{~g} / \mathrm{L}$ & $<1 \mathrm{~g} / \mathrm{L}$ & \\
\hline
\end{tabular}

$>5$ overt DIC; D-dimer 2 instead of 1 and 3 instead of 2 points for moderate and strong increase

dimer increases during the hospital stay in ICU, but not in non-intensive care patients. About 2-fold higher Ddimer in non-survivors was observed in comparison to survivors (manuscript in preparation).

However, DIC is commonly associated with bleeding, after initial microthrombosis in different organs, due to the consumption of coagulation factors, fibrinogen and platelets. Very soon, it was observed that the Covid-19 coagulation abnormalities pattern is different. In the majority of patients prothrombin time (PT) was normal, while fibrinogen was even increased [13]. In our laboratory, we have observed fibrinogen levels approximately 1.5-2 times above the limit of the reference range during intra-hospital course (longer than 2 weeks in the majority of cases), in both survivors and nonsurvivors. Although thrombocytopenia was described in some cohorts $[14,15]$ it does not seem to be a common finding. In our cohort initially normal platelet count was observed, with an increase later during the hospital stay both in ICU and in non-ICU patients (even more significantly in the survivors).

\section{Clinical Manifestations of Coagulation Abnormalities}

Clinical manifestations of coagulation abnormalities are very different. The majority of patients have acute respiratory distress (ARDS) or ARDS like conditions, but many patients experience deep vein thrombosis (DVT) and particularly pulmonary embolism (PE). Some patients have arterial thrombotic events. In one study, it has been observed that $31 \%$ of patients experienced some thrombotic events, primarily venous [17]. The impression of ICU doctors at Karolinska University Hospital is that this number may be even higher (up to 40\%) (personal communication). However, some patients develop peripheral and acro-ischemic necrosis typical of thrombotic microangiopathies (TMA) (including antiphospholipid syndrome (APS) and DIC) [18].

Although an association between Covid-19 and antiphospholipid antibodies (syndrome) has been described $[19,20]$ there is no consensus and several debates have been raised about this issue [21].We at $\mathrm{Ka}$ rolinska University laboratory started to get more samples from patients suspected to have antiphospholipid syndrome (APS), heparin-induced thrombocytopenia (HIT) or thrombotic thrombocytopenic purpura (TTP) like syndromes. All those conditions belong to TMA and may indicate close association between coagulation and inflammation. But we cannot state that we have observed a significant increase of positive results which could indicate a clear association between Covid-19 positivity and the presence of those TMA syndromes. However, some unusual findings such as pseudothrombocytopenia have been described in Covid-19 [22]. This laboratory in-vitro phenomenon caused by platelet aggregation in the tube has been observed in one patient with Covid-19 in our laboratory. The author of this review has never seen HIT associated with platelet aggregation in the tube for 15 years of his laboratory career (some very seldom cases were described in the literature). Therefore, he was completely sure that there was no HIT in that patient. But both rapid (PaGIA) and ELISA tests were strongly positive and the functional platelet aggregation assay was also positive. Most importantly, after the cessation of heparin treatment and its replacement with Apixaban platelets increased. All those findings indicated clinically relevant HIT associated with (if not a consequence of) the Covid-19 infection (manuscript in preparation).

\section{Anticoagulant Treatment in Covid-19}

It has been shown that anticoagulant treatment decreases mortality from Covid-19 [22] and Karolinska University Hospital was among the first to introduce clear recommendations for anticoagulant treatment in these patients. Additionally, some specific recommendations as the double dose prophylaxis in hospitalized patients with, among other risk factors, D-dimer above $3 \mathrm{mg} / \mathrm{L}$ and/or fibrinogen over $8 \mathrm{~g} / \mathrm{L}$ were given by Karolinska University Hospital coagulation experts very early (at the beginning of April 2020). This approach has not been widely accepted yet, and most consensus statement recommendations are based on more conventional standard dose prophylaxis [23]. Interestingly we have observed significant decrease of D-dimer after the introduction of an increased prophylactic LMWH dose (manuscript in preparation). It also seems that such an approach decreases mortality, but final evaluation is yet to be done. 
Table 2 Karolinska University Hospital anticoagulant treatment recommendations

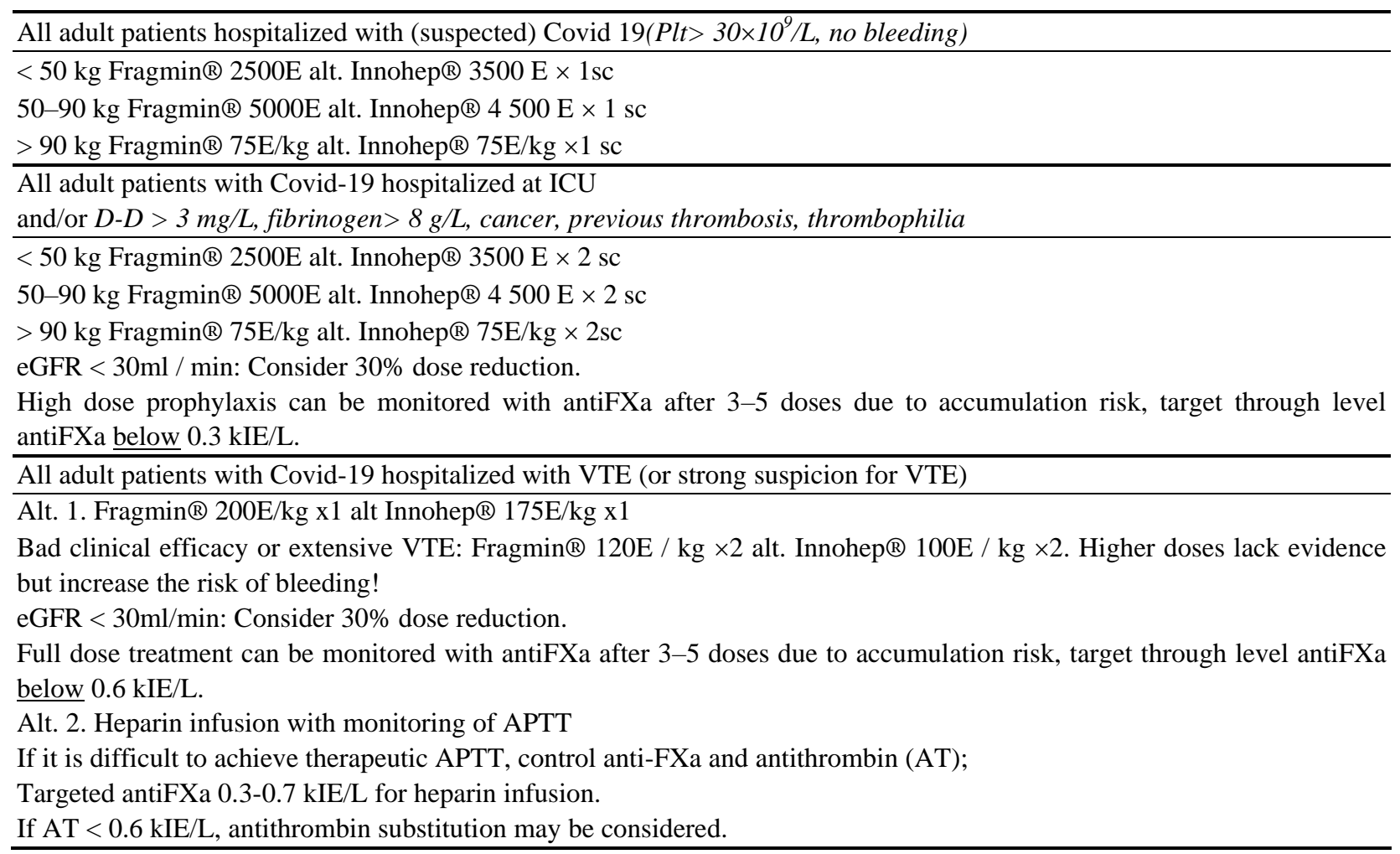

\section{Potential Mechanisms of Thrombo- Inflammatory Conditions in Covid-19}

It seems that the lungs are most severely injured by this virus and that the underlying mechanism is the release of pro-inflammatory cytokines and extravasation of blood cells, primarily neutrophils. At the same time, it is well known that the complement system is an important part of the innate immunity to viral infections. The link between complement and hemostasis has been intensively investigated in recent years [for a review see 24]. Additionally, both microparticles (MP), microvesicles $(<1 \mu \mathrm{m})$ released from different cells after activation and/or apoptosis[25] and neutrophil extracellular traps (NETs)[26] which represent part of the host defense are involved in the signaling process and communication between inflammation/complement and hemostasis. First pathohistological and autopsy reports are now available, and they demonstrate both the deposition of fibrin, neutrophils and C5b-9 and C4d in the lungs and peripheral tissues [27].

MPs, vesicles rich in phosphatidylserine (PS) that carry a subset of parent-cell proteins, are released primarily from platelet and endothelial cells but many other cells may also be the source of MPs and they can carry different proteins including complement, as it has been shown in patients with systemic disease such as vasculitis [28]. It has also been shown in another syndrome (APS), commonly associated with TMA, that thrombin activatable fibrinolysis inhibitor (TAFI), which is included in the stabilization of fibrin, may represent a link between coagulation and complement [29]. In one recent review, it has been discussed the association between brain injury (commonly associated with DIC or DIC-like coagulation abnormalities which have common features as some of Covid-19 coagulopathy), hemostasis and complement [30].

Neutrophil extracellular traps (NETs) were first described in 2004 as a means for neutrophils to trap and kill bacteria and are released as a result of a programmed cell death mechanism referred to as NETosis. The most recent study revealed high levels of NETs in many patients with Covid-19, where they may have contributed to cytokine release and respiratory failure [31].

\section{Are Hemostatic Disturbances in Covid-19 Unique - Implications for Treatment?}

Despite dramatical clinical and laboratory findings and massive overload of "scientific" information (at the moment of writing this article (mid-June 2020) more than 20,000 articles including the term Covid are available on PubMed) based mostly on case-reports and small series of patients (published without a thorough peer-review process) medical practitioners dealing with thrombosis and hemostasis have to keep the ability for logical decision making based on scientific evidences. Therefore, we should carefully think about the fact that increased D-dimer is common in hospitalized and criti- 
cally ill patients [32-34] but is not routinely measured on a daily basis in other patients as is currently being done in patients with COVID-19 [35]. Increased incidence of VTE is not exclusively present in Covid-19. Even in other viral influenza $(\mathrm{H} 1 \mathrm{~N} 1)$ it was observed that severe patients with ARDS who were positive to H1N1 had 20-fold higher risk to develop VTE, and anticoagulation dramatically decreased that risk [36].

Nevertheless, it seems that apart from ARDS or ARDS like syndromes some kind of thromboembolic complications (mostly VTE) are present in about one third of severe (mostly ICU) patients with Covid-19. However, one should be reminded that venous thromboembolism was present in approximately the same (or even higher, up to $40 \%$ ) percentage on routine autopsies and that the number was the same within several decades $[37,38]$. The same number of VTE $(40 \%)$ was found in the very first larger series of autopsies of patients who died after Covid-19 [39]. Interestingly enough, although now there is a definite consensus that coagulation abnormalities in Covid-19 are not similar to those in DIC, mortality in overt DIC is also described to be about $40 \%$ [40]. So almost a philosophical question should be raised: are hemostatic abnormalities something that happens at the end of life in severely ill patients irrespectively of whether they have Covid-19, another influenza or some other severe terminal disease? It also seems that the proinflammatory response is also a part of those pathophysiological conditions.

Taking into account the preliminary results that the use of anticoagulation not only decreases the incidence of VTE but also seems to improve the outcome of severe patients with Covid-19, a question may be posed the other way round: Should (all) severely ill patients may experience the benefit of increased anticoagulation prophylaxis?

Table 3 Karolinska University Hospital coagulation findings in patients with severe Covid-19

\begin{tabular}{lcc}
\hline Analysis & Change & Kinetics during hospitalization \\
\hline PT-INR & $\mathrm{N}$ & $\rightarrow$ \\
Fibrinogen & $\uparrow \uparrow$ & $\rightarrow$ \\
Platelet count & $\mathrm{N} / \uparrow$ & $\uparrow^{*}$ \\
D-dimer & $\uparrow$ & $\uparrow \uparrow$ \\
\hline
\end{tabular}

$\mathrm{N}$-normal, $\uparrow$ increase, $\uparrow \uparrow$ major increase, $\rightarrow$ preserve on initial level.

*Non-survivors had slight platelet count decrease (within reference range between day 5 and 10).

\section{References}

1. Giwa A, Desai A. Novel coronavirus COVID-19: an overview for emergency clinicians. Emerg Med Pract 2020; 22(2 Suppl 2):1-21. https://pubmed.ncbi.nlm.nih.gov/32105049/1. Update in: Emerg Med Pract. 2020; 22(5):1-28. https://www.ebmedicine. net/topics/infectious-disease/COVID-19.

2. Guan WJ, Ni ZY, Hu Y, Liang WH, Ou CQ, He JX, et al. for China Medical Treatment Expert Group for Covid-19. Clinical Characteristics of Coronavirus Disease 2019 in China. N Engl J Med 2020; 382(18):1708-1720. doi: 10.1056/NEJMoa2002032

\section{Instead of Conclusions}

To summarize what is known about thrombo-inflammatory abnormalities in Covid-19 (both from the literature and from Karolinska University Hospital experience):

1. High levels of inflammatory markers, particularly IL-6, neutrophils, fibrinogen and D-dimer are present and are associated with prognosis;

2. Almost $40 \%$ of severe patients apart from ARDSlike phenomena develop thrombosis, predominantly VTE/PE but also arterial thrombosis and TMA type changes in peripheral organs including acro-necrosis;

3. Pathophysiologically, complement-neutrophilsfibrin deposition is present in affected tissues (primarily the lungs);

4. Increase of the prophylactic dose of heparin/LMWH seems to be justified in the prevention of thrombosis.

What is not certainly known:

1. Is thrombocytopenia or thrombocytosis more common in Covid-19 patients?

2. Is the mechanism behind large vessel thrombosis and TMA the same?

3. How to diagnose thrombosis?

4. How to manage thrombosis (primarily VTE/PE) not responding to the standard treatment?

5. Is there a place for antiplatelet treatment in addition to anticoagulation treatment?

6. Does the level of complement activation correlate with the development of thrombosis propensity and severe pulmonary engagement?

7. Are there changes in additional modulators of hypercoagulability, such as microparticles and neutrophil extracellular traps, which contribute to the complex interplay of hemostasis, inflammation and the SARS-Cov2 infection?

Hemostatic abnormalities including VTE are common in Covid-19 and it seems that increased anticoagulant prophylaxis may be beneficial for severe (ICU/mechanical ventilation) patients. However, the importance of those changes should not be overestimated since it seems that thromboembolic phenomena are, to a similar extent, present in other influenza and severely ill patients.
3. Rolf JD. Clinical Characteristics of Covid-19 in China. N Engl J Med 2020; 382(19):1860. doi: 10.1056/NEJMc2005203.

4. Huang C, Wang Y, Li X, Ren L, Zhao J, Hu Y, et al. Clinical features of patients infectedwith 2019 novel coronavirus in Wuhan, China. Lancet 2020; 395(10223):497-506. doi: 10.1016/S0140-6736(20)30183-5. Erratum in: Lancet 2020. doi: $10.1016 / \mathrm{S} 0140-6736(20) 30252-\mathrm{X}$ 
5. Chen L, Liu H-G, Liu W, Liu J, Liu K, Shang J, et al. Analysis of clinical features of 29 patients with 2019 novel coronavirus pneumonia. Chin J Tuberc Respir Dis 2020; 43(0):E005. (Chinese) doi: 10.3760/cma.j.issn.1001-0939.2020.0005

6. Ye Q, Wang B, Mao J. The pathogenesis and treatment of the 'Cytokine Storm' in COVID-19. J Infect 2020; 80(6):607-613. doi: 10.1016/j.jinf.2020.03.037

7. Tang N, Li D, Wang X, Sun Z. Abnormal coagulation parameters are associated with poor prognosis in patients with novel coronavirus pneumonia. J Thromb Haemost 2020;18: 844-847. doi: $10.1111 /$ jth. 14768

8. Lippi G, Plebani M. Laboratory abnormalities in patients with COVID-2019 infection. Clin Chem Lab Med 2020. doi: 10.1515/cclm-2020-0198

9. Zhou F, Yu T, Du R, Fan G, Liu Y, Liu Z, et al. Clinical course and risk factors for mortality of adult inpatients with COVID-19 in Wuhan, China: a retrospective cohort study. Lancet 2020; 395(10229):1054-1062. doi: 10.1016/S0140-6736(20)30566-3. Erratum in: Lancet 2020; 395(10229):1038. doi: 10.1016/S01406736(20)30639-5

10. Wu C, Chen X, Cai Y, Xia J, Zhou X, Xu S, et al. Risk factors associated with acute respiratory distress syndrome and death in patients with coronavirus disease 2019 pneumonia in Wuhan, China. JAMA Intern Med 2020; 180(7):934-943. doi: 10.1001/jamainternmed.2020.0994

11. Guan WJ, Ni ZY, Hu Y, Liang WH, Ou CQ, He JX, et al for China Medical Treatment Expert Group for Covid-19. Clinical Characteristics of Coronavirus Disease 2019 in China. N Engl J Med 2020; 382(18):1708-1720. doi: 10.1056/NEJMoa2002032

12. Zhang L, Yan X, Fan Q, Liu H, Liu X, Liu Z, et al. D-dimer levels on admission to predict in-hospital mortality in patients with Covid-19. J Thromb Haemost 2020: 18(6):1324-1329. doi: 10.1111/jth. 14859

13. Spiezia L, Boscolo A, Poletto F, Cerruti L, Tiberio I, Campello E, et al. Covid-19-related severe hypercoagulability in patients admitted to intensive care unit for acute respiratory failure. Thromb Haemost. 2020; 120(6):998-1000. doi: 10.1055/s-00401710018

14. Yang $\mathrm{X}$, Yang Q, Wang Y, Wu Y, Xu J, Yu Y, et al. Thrombocytopenia and its association with mortality in patients with COVID-19. J Thromb Haemost 2020; 18(6):1469-1472. doi: $10.1111 /$ jth. 14848

15. Lippi G, Plebani M, Henry BM. Thrombocytopenia is associated with severe coronavirus disease 2019 (COVID-19) infections: A meta-analysis. Clin Chim Acta 2020; 506:145-148. doi: 10.1016/j.cca.2020.03.022

16. Toh $\mathrm{CH}$, Hoots WK; SSC on Disseminated Intravascular Coagulation of the ISTH. The scoring system of the Scientific and Standardisation Committee on Disseminated Intravascular Coagulation of the International Society on Thrombosis and Haemostasis: a 5-year overview. J Thromb Haemost 2007; 5(3):604-606. doi: 10.1111/j.1538-7836.2007.02313.x

17. Llitjos JF, Leclerc M, Chochois C, Monsallier JM, Ramakers M, Auvray M, Merouani K. High incidence of venous thromboembolic events in anticoagulated severe COVID-19 patients. J Thromb Haemost 2020; 18: 1743-1746. doi: 10.1111/jth.14869

18. Zhang Y, Cao W, Xiao M, Li YJ, Yang Y, Zhao J, et al. [Clinical and coagulation characteristics in 7 patients with critical COVID2019 pneumonia and acro-ischemia]. ZhonghuaXue Ye Xue Za Zhi 2020;41(4):302-307. Chinese. doi: 10.3760/cma.j.issn.02532727.2020.0006

19. Hossri S, Shadi M, Hamarsha Z, Schneider R, El-Sayegh D. Clinically significant anticardiolipin antibodies associated with COVID-19. J Crit Care 2020; 59:32-34. doi: 10.1016/j.jcrc. 2020.05.017.

20. Harzallah I, Debliquis A, Drénou B. Lupus anticoagulant is frequent in patients with Covid-19. J Thromb Haemost 2020: 18(8):2064-2965. doi: 10.1111/jth. 14867
21. Tang N. Response to "Lupus anticoagulant is frequent in patients with Covid-19". J Thromb Haemost 2020; 18(8): 2065-2066. doi: $10.1111 /$ jth. 14890

22. Tang N, Bai H, Chen X, Gong J, Li D, Sun Z. Anticoagulant treatment is associated with decreased mortality in severe coronavirus disease 2019 patients with coagulopathy. J Thromb Haemost. 2020; 18(5):1094-1099. doi: 10.1111/jth.14817.

23. Spyropoulos AC, Levy JH, Ageno W, Connors JM, Hunt BJ, Iba $\mathrm{T}$, et al. for Subcommittee on Perioperative, Critical Care Thrombosis, Haemostasis of the Scientific, Standardization Committee of the International Society on Thrombosis, Haemostasis. Scientific and Standardization Committee Communication. Clinical Guidance on the Diagnosis, Prevention and Treatment of Venous Thromboembolism in Hospitalized Patients with COVID-19. J Thromb Haemost 2020; 18(8): 1859-1865. doi: 10.1111/jth.14929

24. Conway EM. Complement-coagulation connections. Blood Coagul Fibrinolysis 2018; 29(3):243-251. doi: 10.1097/MBC. 0000000000000720

25. Karasu E, Eisenhardt SU, Harant J, Huber-Lang M. Extracellular Vesicles: Packages Sent With Complement. Front Immunol 2018; 9:721. doi: 10.3389/fimmu.2018.00721.

26. de Bont CM, Boelens WC, Pruijn GJM. NETosis, complement, and coagulation: a triangular relationship. Cell Mol Immunol 2019; 16(1):19-27. doi: 10.1038/s41423-018-0024-0

27. Magro C, Mulvey JJ, Berlin D, Nuovo G, Salvatore S, Harp J, Baxter-Stoltzfus A, Laurence J. Complement associated microvascular injury and thrombosis in the pathogenesis of severe COVID-19 infection: a report of five cases. Transl Res 2020; 220: 1-13. doi: 10.1016/j.trs1.2020.04.007

28. Antovic A, Mobarrez F, Manojlovic M, Soutari N, De Porta Baggemar V, Nordin A, et al. Microparticles Expressing Myeloperoxidase and Complement C3a and C5a as Markers of Renal Involvement in Antineutrophil Cytoplasmic Antibodyassociated Vasculitis. J Rheumatol 2020; 47(5):714-721. doi: 10.3899/jrheum. 181347

29. Grosso G, Vikerfors A, Woodhams B, Adam M, Bremme K, Holmström M, et al. Thrombin activatable fibrinolysis inhibitor (TAFI) - A possible link between coagulation and complement activation in the antiphospholipid syndrome (APS). Thromb Res 2017; 158:168-173. doi: 10.1016/j.thromres.2017.06.028

30. Fletcher-Sandersjöö A, Maegele M, Bellander BM. Does complement-mediated hemostatic disturbance occur in traumatic brain injury? A literature review and observational study protocol. Int J Mol Sci 2020; 21(5):1596. doi: 10.3390/ijms21051596

31. Zuo Y, Yalavarthi S, Shi H, Gockman K, Zuo M, Madison JA, et al. Neutrophil extracellular traps in COVID-19. JCI Insight 2020; 5(11):138999. doi: 10.1172/jci.insight.138999

32. Goldhaber SZ. The perils of D-dimer in the medical intensive care unit. Crit Care Med 2000; 28(2):583-584. doi: 10.1097/ 00003246-200002000-00056

33. Shorr AF, Thomas SJ, Alkins SA, Fitzpatrick TM, Ling GS. Ddimer correlates with proinflammatory cytokine levels and outcomes in critically ill patients. Chest $2002 ; 121(4)$ :1262-1268. doi: 10.1378/chest.121.4.1262

34. Lindblad B, Sternby NH, Bergqvist D. Incidence of venous thromboembolism verified by necropsy over 30 years. BMJ. 1991; 302(6778):709-711. doi: 10.1136/bmj.302.6778.709

35. Clark CL, Shams AH, Chang AM, Ferman GJ, Hiestand BC, Kea $\mathrm{B}$, et al. D-dimer in acute medically ill adults and current thromboprophylaxis: A multicenter observational study evaluating the prevalence of elevated D-dimer in acute medically ill, hospitalized adults and current thromboprophylaxis trends; the DAMIACT Study, initial data analysis. Res Pract Thromb Haemost 2017; 1(S1):567-568. doi: 10.1002/rth2.12012

36. Al-Samkari H, Karp Leaf RS, Dzik WH, Carlson JC, Fogerty AE, Waheed A, et al. COVID and coagulation: bleeding and thrombotic manifestations of SARS-CoV2 infection. Blood 2020; 136(4): 489-500. doi: 10.1182/blood.2020006520 
37. Obi AT, Tignanelli CJ, Jacobs BN, Arya S, Park PK, Wakefield TW, et al. Empirical systemic anticoagulation is associated with decreased venous thromboembolism in critically ill influenza A H1N1 acute respiratory distress syndrome patients. J Vasc Surg Venous Lymphat Disord 2019; 7(3):317-324. doi: 10.1016/j.jvsv.2018.08.010. Erratum in: J Vasc Surg Venous Lymphat Disord 2019; 7(4):621. doi: 10.1016/j.jvsv.2019.05.001

38. Diebold J, Löhrs U. Venous thrombosis and pulmonary embolism. A study of 5039 autopsies. Pathol Res Pract 1991; 187(2-3):260-266. doi: 10.1016/S0344-0338(11)80781-8
39. Edler C, Schröder AS, Aepfelbacher M, Fitzek A, Heinemann A, Heinrich F, et al. Dying with SARS-CoV-2 infection-an autopsy study of the first consecutive 80 cases in Hamburg, Germany. Int J Legal Med 2020; 134:1275-1284. doi: 10.1007/s00414-02002317-w

40. Gando S, Levi M, Toh CH. Disseminated intravascular coagulation. Nat Rev Dis Primers 2016; 2:16037. doi: 10.1038/nrdp.2016.37 